\title{
Measuring accurate IOPs: Does correction factor help or hurt?
}

This article was published in the following Dove Press journal:

Clinical Ophthalmology

24 June 2010

Number of times this article has been viewed

\section{Pinakin Gunvant' \\ Robert D Newcomb 2 \\ Elliot M Kirstein ${ }^{3}$ \\ Victor E Malinovsky ${ }^{4}$ \\ Richard J Madonna ${ }^{5}$ \\ Richard E Meetz ${ }^{4}$}

'Southern College of Optometry, Memphis, Tennessee, USA; ${ }^{2}$ The Ohio State University College of Optometry, Columbus, Ohio, USA; ${ }^{3}$ The Glaucoma and Diabetes Eye Institute, Cincinnati, Ohio, USA; ${ }^{4}$ Indiana University School of Optometry, Bloomington, Indiana, USA; ${ }^{5}$ State University of New York College of Optometry, New York, USA

Correspondence: Pinakin Gunvant Southern College of Optometry, 1245 Madison Avenue, Memphis, TN 38104, USA

Tel + I-90I-722-3357

Fax $+|-90|-722-3325$

Email contact@pinakin-gunvant.com
Purpose: To evaluate if using the Ehlers correction factor on the intraocular pressure (IOP) measured using the Goldmann applanation tonometer (GAT) improves its agreement with the PASCAL dynamic contour tonometer (DCT).

Patients and methods: A total of 120 eyes of 120 individuals were examined. Participants underwent IOP measurement with both the DCT and the GAT and central corneal thickness measurement. The Ehlers correction factor was applied on the GAT IOP measurements to calculate Ehlers-corrected GAT IOP. The agreement between the DCT and GAT, and DCT and Ehlers-corrected GAT IOP was analyzed. The analyses were repeated by stratifying the data by race.

Results: The mean IOP of the GAT, DCT, and the Ehlers-corrected GAT was 15.30, 16.78, and $14.68 \mathrm{mmHg}$, respectively. The agreement as assessed by Bland-Altman plot for the GAT with the DCT and DCT and Ehlers-corrected GAT IOP was +4.1 to -6.9 and +4.15 to $-8.25 \mathrm{mmHg}$, respectively. The results were similar even when stratifying the data by race.

Conclusion: Using Ehlers correction factor to account for the effect of corneal parameters on the IOP measured by the GAT worsens the agreement with the DCT. This effect remains even when stratifying the data by race.

Keywords: dynamic contour tonometer, Goldmann applanation tonometer, tonometric correction factors, central corneal thickness, intraocular pressure

Goldmann applanation tonometry has enjoyed the status of being the gold standard in tonometry for many years and is the most widely used tonometer in clinical practice. The Goldmann applanation tonometer (GAT) measures the intraocular pressure (IOP) by applanating a surface area of $3.06 \mathrm{~mm}$ of the central cornea. However, central corneal thickness (CCT) in a population varies widely and ranges from 440 to $640 \mu \mathrm{m}$. Due to this wide variation, the measured IOP is often erroneous, particularly in the eyes in which the CCT is significantly different when compared with the mean CCT of the population. Ehlers et $\mathrm{al}^{1}$ by using intracameral IOP (manometry) experiments showed that there was a systematic variation in the IOP measured using the GAT with the variation of CCT. Ehlers et $\mathrm{al}^{1}$ observed that IOP is measured erroneously higher in eyes with CCT more than normal, whereas the IOP is measured erroneously lower in eyes with CCT less than normal. Ehlers et al $^{1}$ proposed a nomogram that is used to date in clinics to correct the IOP measured using GAT (Goldmann IOP) for the errors induced due to variation in CCT.

The PASCAL ${ }^{\circledR}$ dynamic contour tonometer (DCT; Ziemer Ophthalmology, Port, Switzerland) is a contact tonometer that is reported to be repeatable ${ }^{2-5}$ and measures IOP independent of the effects of the CCT. ${ }^{6-13}$ It is shown with manometry experiments that unlike 
in the GAT, IOP measured using the PASCAL DCT (PASCAL IOP) does not vary systematically with CCT and closely replicates the IOP measurements obtained with manometry. ${ }^{14,15}$

The aim of the study was to evaluate the validity of the Ehlers nomogram in correcting the Goldmann IOP. If the Ehlers correction nomogram works well in aiding to eliminate the errors due to the variation of CCT, the following will be expected: 1) the Ehlers-corrected GAT IOP (Ehlers IOP) would have good agreement with the PASCAL IOP. 2) Further, the agreement between Ehlers IOP and PASCAL IOP will be better than the agreement between Goldmann IOP and PASCAL IOP.

Ehlers algorithm was primarily derived from a population that was composed of Caucasians. ${ }^{1} \mathrm{CCT}$ and corneal biomechanics are reported to vary among different races, and African Americans on an average have thinner central cornea when compared with Caucasians. ${ }^{16-18}$ The study participants included both Caucasian and African American individuals. Thus, an additional aim was to stratify the data on the basis of self-reported race and examine the validity of the Ehlers nomogram as a function of race.

\section{Methods}

The study was advertised and participants were examined at one of the following five locations: 1) Department of Research, Southern College of Optometry, 2) The Ohio State University College of Optometry, 3) The Glaucoma and Diabetes Eye Institute, 4) Indiana University School of Optometry, and 5) State University of New York, College of Optometry. The institutional review board approved the study at individual sites, and the tenets of the Declaration of Helsinki were observed. Data management conformed to Health Insurance Portability and Accountability Act (HIPPA) regulations. Written informed consent was obtained from all study participants. The investigators of the study were not aware of the participants' measurements prior to the study.

Each study participant underwent ophthalmic examination, including external eye evaluation with a slit lamp biomicroscope and retinal evaluation. Individuals with corneal diseases or with a history of intraocular surgery were not included in the study. Only one eye of an individual was included in the data analysis for the study. All study measurements were performed prior to the pupil dilation. A total of 120 eyes of 120 individuals were included in the study. Of these, 81 were women and 39 were men; 88 individuals were Caucasian and 32 were African American ancestries.

\section{Measurement of IOP}

Subjects underwent IOP measurement with a GAT and a PASCAL DCT, which were mounted on a slit lamp.
The sequence of measurement was randomized with all participants. All measurements were performed by experienced observers who are the authors of this study. A drop of Fluress (benoxinate $0.4 \%$ with fluorescein sodium $0.25 \%$ ) was instilled prior to the measurement of IOP with the GAT. A drop of proparacaine $0.5 \%$ was instilled before the measurement of IOP with the PASCAL DCT. The PASCAL DCT measures pressure continuously as long as it is in adequate contact to the eye. The tonometer gives out a whistling sound, the rhythm of which coincides with the ocular pulse and the cardiac cycle. It is recommended that the IOP be measured for a period of 6-8 cardiac cycles. The instrument's software gives a quality score that ranges from 1 to 5 , with 1 being the best reading and 5 being the worst reading. All measurements performed in the study had a quality reading of $1-3$.

\section{Central corneal thickness}

Because reliable and accurate measurement of CCT was of paramount importance for the present study, all centers used a pachymeter that was obtained from the same manufacturer. The ultrasonic pachymeter that was used to measure CCT was Corneo-Gage $^{\mathrm{TM}}$ Plus from Sonogage, Cleveland, Ohio. This instrument uses a $50-\mathrm{MHz}$ ultrasonic probe, which gives a 2.5 times better resolution when compared with other commercially available pachymeters, which uses a $10-$ to $20-\mathrm{MHz}$ probe. The subject's eye was anesthetized with a drop of proparacaine $0.5 \%$. Subjects were instructed to keep the eye closed for 30 seconds to 1 minute to ensure good anesthesia. Measurements were performed in rapid succession (up to 10 readings), and the lowest was taken as the CCT. Patients were instructed to blink after each measurement to avoid desiccation of the corneal epithelium. Measurements performed in this fashion are reported to be repeatable and reproducible. ${ }^{19}$

\section{Statistical analysis}

Ehlers IOP was calculated from the Goldmann IOP using the nomogram published by Ehlers et al. ${ }^{1}$ Paired-samples $t$-test was used to evaluate the difference in IOP measured using the GAT and the PASCAL DCT. Pearson correlation coefficient ( $r$ ) was used to evaluate the associations between CCT and the Goldmann and PASCAL IOPs, and the difference between Goldmann IOP and the PASCAL IOP. Linear regression was used to analyze the residual association between the CCT and the difference in Ehlers IOP and PASCAL IOP. Both the Goldmann IOP and the Ehlers IOP were compared with the PASCAL IOP using Bland-Altman plots to assess the agreement between IOP values. Patients were stratified on the basis of self-reported race, and the agreement between IOP values was examined. 


\section{Results}

As known previously, CCT has a weak yet statistically significant positive correlation with the IOP measured by the GAT ( $r=0.20, P=0.03$; Figure 1$)$; that is, the Goldmann IOP increases with increase in CCT. However, there is no association between the CCT and the PASCAL IOP $(r=0.02$, $P=0.84$; Figure 2). The difference in the Goldmann IOP and the PASCAL IOP was related to the measured CCT, indicating that part of the difference in IOP can be accounted by the physiological variation in CCT $(r=0.18, P=0.04$; Figure 3$)$. The difference in the Goldmann IOP and the PASCAL IOP was significant $(P<0.0001)$.

Examining the limits of agreement between the Goldmann IOP and the PASCAL IOP by using Bland-Altman plots, we find that the limits of agreement are wide, with the lower limit of agreement being $-6.9 \mathrm{mmHg}$ and the upper limit of agreement being $+4.1 \mathrm{mmHg}$ (Figure 4). There is no systematic error in measurement, and the difference in IOP measured using the two devices did not vary as a function of the IOP.

\section{Evaluation of Ehlers IOP and PASCAL IOP}

Examining the limits of agreement between the Ehlers IOP and the PASCAL IOP, we find that the limits of agreement are wider than that of the Goldmann IOP and PASCAL IOP with the lower limit of agreement being $-8.25 \mathrm{mmHg}$ and upper limit of agreement being $+4.15 \mathrm{mmHg}$ (Figure 5).

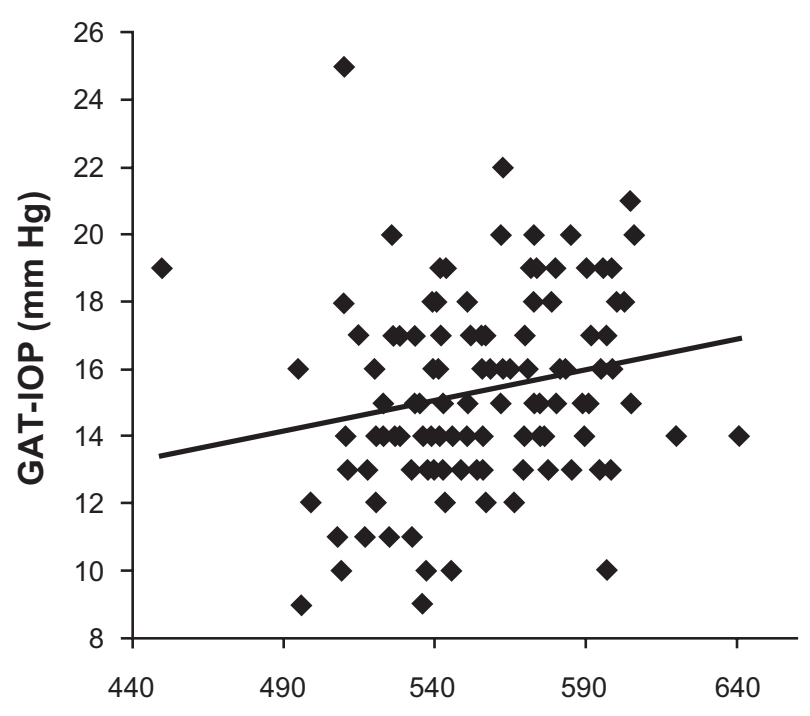

Central corneal thickness (microns)

Figure I Scatterplot showing the association between the central corneal thickness and intraocular pressure measured by the Goldmann applanation tonometer. There is a linear positive trend with measured intraocular pressure being lesser in eyes with lower-than-average central corneal thickness and greater with higher-thanaverage central corneal thickness.

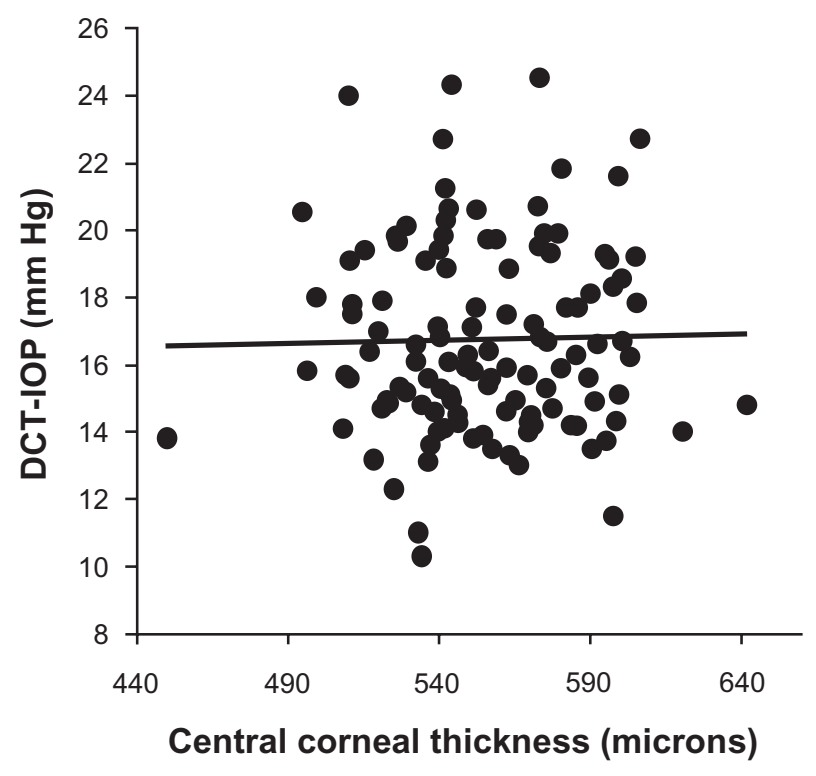

Figure 2 Scatterplot showing the association between the central corneal thickness and intraocular pressure measured by the PASCAL dynamic contour tonometer. The trend line is flat indicating no association between the two variables.

Linear regression analysis indicates that there is a negative trend when comparing Ehlers IOP and the PASCAL IOP, which indicate an overcorrection of IOP (Figure 6).

\section{Ehlers nomogram and race}

The study included individuals from both Caucasian and African American ancestries. The trends were similar even when groups were segregated by race, with limits of

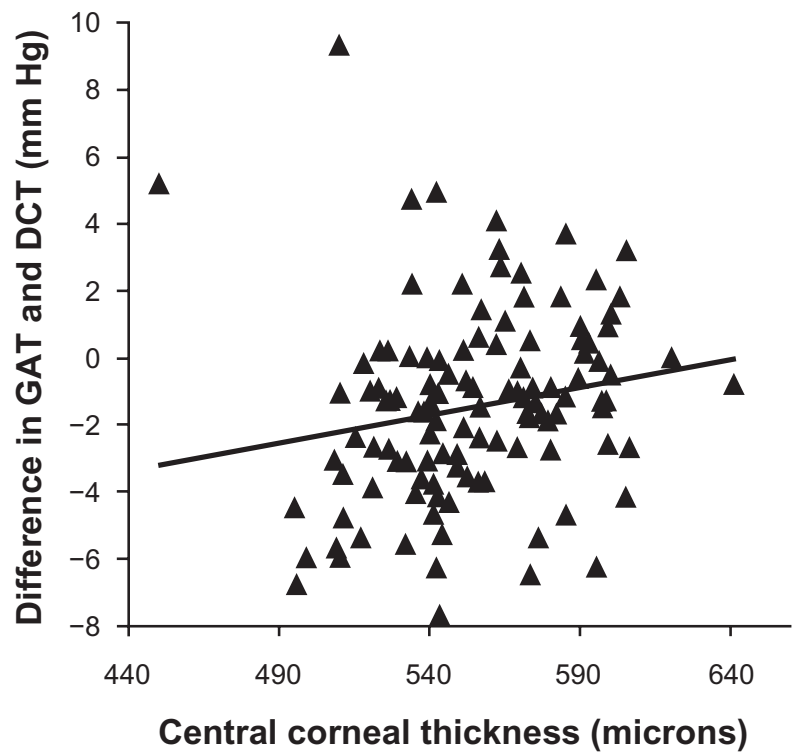

Figure 3 Scatterplot showing the association between the central corneal thickness and the difference in intraocular pressure measured by the Goldmann applanation tonometer and the PASCAL dynamic contour tonometer. There is a linear positive trend with difference in intraocular pressure being negative in eyes with lowerthan-average central corneal thickness and positive with higher-than-average central corneal thickness. This indicates that the difference in intraocular pressure may be accounted in part by central corneal thickness. 


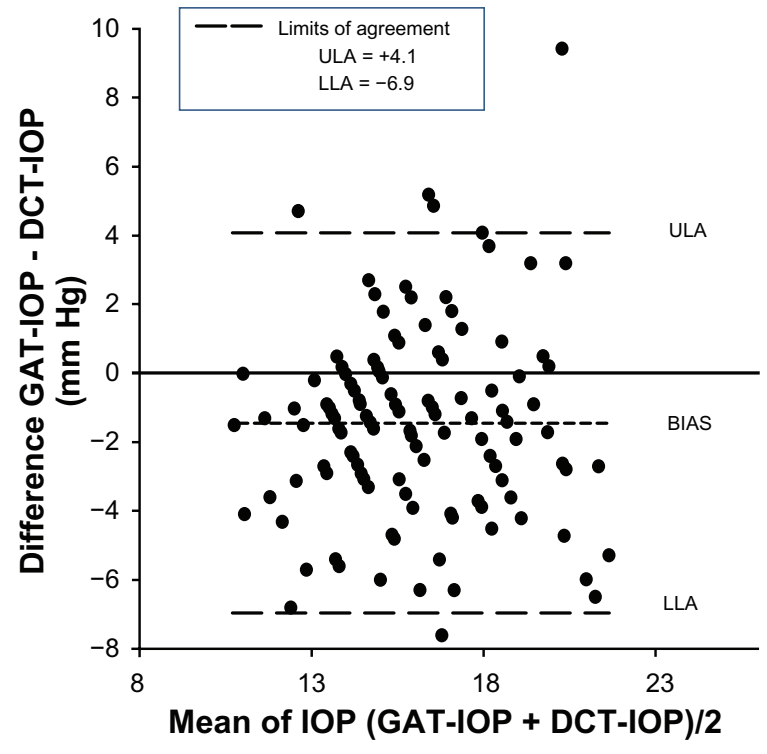

Figure $4 \mathrm{~A}$ Bland-Altman plot assesses the agreement between intraocular pressure values measured using the Goldmann applanation tonometer and the PASCAL dynamic contour tonometer. The upper limit of agreement (ULA) and the lower limit of agreement (LLA) are wide, indicating that agreement between the two tonometers is poor. The bias line is negative, indicating that the PASCAL dynamic contour tonometer on average measures greater intraocular pressure when compared with the Goldmann applanation tonometer.

agreement between the Ehlers IOP and the PASCAL IOP being wider, in both the Caucasian and African American ancestries when compared with limits of agreement between the Goldmann IOP and the PASCAL IOP. The

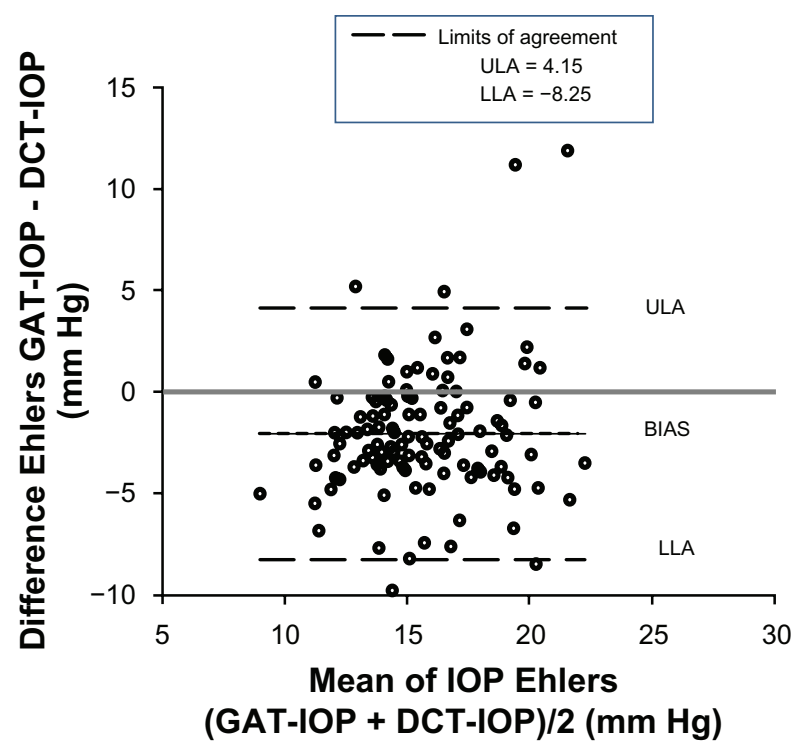

Figure 5 A Bland-Altman plot assesses the agreement between intraocular pressure values measured using the PASCAL dynamic contour tonometer and the Ehlers intraocular pressure calculated from the Goldmann intraocular pressure measurements. The upper limit of agreement (ULA) and the lower limit of agreement (LLA) are wide, indicating that agreement between the intraocular pressure values is poor. The bias line is negative, indicating that the Ehlers intraocular pressure on average is lower than the intraocular pressure measured by the PASCAL dynamic contour tonometer.

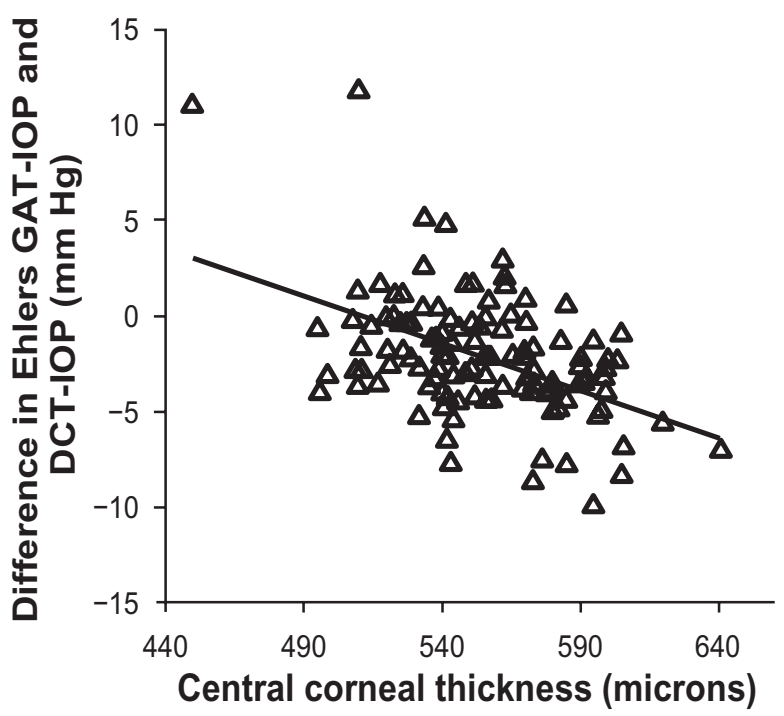

Figure 6 Scatterplot showing the residual association between the central corneal thickness and difference between the Ehlers intraocular pressure and the PASCAL dynamic contour tonometer; a linear negative trend is visible.

limits of agreement of various comparisons are shown in Table 1.

\section{Discussion}

The IOP measured by the GAT is affected by CCT as shown by Ehlers et $\mathrm{al}^{1}$ and numerous other studies subsequently. ${ }^{20-26}$ However, studies have shown that the IOP estimates obtained using the PASCAL DCT is independent of the effect of CCT. ${ }^{6-13}$ Furthermore, the IOP estimates obtained by the PASCAL DCT closely matches the manometry values, ${ }^{14,15}$ making it a closer representation to the "true IOP" when compared with the Goldmann IOP. A portion of the difference in the measured values and agreement between the Goldmann IOP and the PASCAL IOP is attributed to the errors in tonometry induced by the physiological variations in biomechanical properties of the cornea. ${ }^{14,15}$

If the Ehlers correction nomogram was indeed correct and used on the Goldmann IOP to correct for CCT, it is expected that the agreement with the PASCAL IOP should improve. This study shows that the limits of agreement between the Ehlers IOP and the PASCAL IOP are wider than that of the agreement between Goldmann IOP and PASCAL IOP, indicating that correcting the Goldmann IOP for the errors in CCT may in fact worsen the estimate of IOP and widen the difference from the "True IOP" in eye. Further, it was apparent from the negative trend observed in the regression analysis (Figure 6) that the Ehlers nomogram ${ }^{1}$ overcorrects and overestimates the effect of the CCT on IOP. Furthermore, 
Table I Agreement between the intraocular pressure by various methods

\begin{tabular}{llll}
\hline $\begin{array}{l}\text { Bland-Altman } \\
\text { plots }\end{array}$ & $\begin{array}{l}\text { Overall } \\
(\mathbf{n}=\mathbf{I 2 0}) \mathbf{9 5 \%} \mathbf{C l}\end{array}$ & $\begin{array}{l}\text { Caucasian } \\
\mathbf{( n = 8 8 )} \mathbf{9 5 \%} \mathbf{~ C l}\end{array}$ & $\begin{array}{l}\text { African American } \\
\mathbf{( n = 3 2 )} \mathbf{9 5 \%} \mathbf{~ C l}\end{array}$ \\
\hline $\begin{array}{l}\text { Goldmann IOP and } \\
\text { PASCAL IOP }\end{array}$ & -6.9 to +4.10 & -4.06 to +5.60 & -2.50 to +9.02 \\
$\begin{array}{l}\text { Ehlers IOP and PASCAL } \\
\text { IOP }\end{array}$ & -8.25 to +4.15 & -3.99 to +7.57 & -4.38 to +9.91 \\
\hline
\end{tabular}

Notes: $\mathrm{Cl}$, confidence interval; Goldmann IOP, the intraocular pressure measured using the Goldmann applanation tonometer; PASCAL IOP, the intraocular pressure measured using the PASCAL dynamic contour tonometer; Ehlers IOP, the value obtained by applying Ehlers correction factor to the intraocular pressure measured using the Goldmann applanation tonometer.

the corneal thickness may be only a part of the error in tonometry and parameters like corneal rigidity and hydration may affect corneal biomechanics and are other sources of errors in tonometry. This study is additional evidence to a finding that was reported in a prior study, ${ }^{27}$ which showed the effect of CCT on IOP after correcting it with the Ehlers nomogram.

This study shows that the Ehlers nomogram did not improve the agreement even when the participants were stratified by race. This is interesting because it was expected that the Ehlers nomogram would be more accurate for the individuals with Caucasian origin as the participants in Ehlers et al ${ }^{1}$ study were primarily of Caucasian origin, and there would be an increased similarity of ocular parameters like the corneal thickness, corneal curvature, and axial length. There could be a few reasons why the Ehlers IOP was not in agreement with the PASCAL IOP. The Ehlers correction factor was derived from manometry experiments, and although manometry is the best direct measure of IOP, it is not free from errors. Manometry results can be significantly erroneous if the needle that is used for cannulation of the eye is blocked by air bubbles or particles. ${ }^{28}$ Further, the manometry experiments performed by Ehlers et al ${ }^{1}$ also included patients with acute angle - closure glaucoma who were undergoing surgery for glaucoma. This could have a significant impact because there are changes in biomechanical properties of the cornea that has edema secondary to angle closure. Also, there could be other factors that may account for the differences in the Goldmann IOP and the PASCAL IOP, such as the age-related and physiological variation in the hydration of cornea, which cannot be measured in vivo at present time. Other studies that have examined the effect of CCT on Goldmann IOP have also discounted the benefit of using the correction algorithms that are solely based on corneal thickness because the error in tonometry due to corneal parameters is multidimensional, of which corneal thickness is a small part of the equation and may not aid in better clinical care or outcome..$^{10,29,30}$

There are other correction algorithms that are present as an alternative to Ehlers correction factor, ${ }^{1}$ notably, the Orssengo-Pye algorithm, ${ }^{31}$ which is based on finite element analysis and does not assume linearity as done by the Ehlers correction factor. Prior work has shown that the Orssengo-Pye algorithm is in agreement with the Ehlers correction factor. ${ }^{31}$ Using the Orssengo-Pye algorithm ${ }^{31}$ to calculate IOP correction requires the need of having corneal curvature details, which were not available in the present study, and thus, we were not able to evaluate its efficacy.

This study is in agreement with prior studies and showed that there was a systematic error in the GAT-measured IOP, with physiological variation of CCT. ${ }^{20-26}$ This study also confirms the finding that the IOP measured by the PASCAL DCT is less affected by the variation in CCT when compared with the Goldmann GAT. ${ }^{12,13,32,33}$ Thus, it may, in fact, be a better tonometer when compared with the Goldmann GAT in measuring IOP. There is a definite need to estimate the IOP accurately because the current treatment and management of glaucoma, to an extent, are based on the level of IOP. However, the results from this study indicate that the use of Ehlers nomogram ${ }^{1}$ to correct for the error induced due to CCT is not advisable, as it may be increasing the error rather than decreasing it.

\section{Disclosure}

Pinakin Gunvant, Robert D Newcomb, Elliot M Kirstein, Victor E Malinovsky, Richard J Madonna, and Richard E Meetz report no conflicts of interest in this work. Elliot M Kirstein is a paid research coordinator for Ziemer Ophthalmology AG, Port, Switzerland, who market and sells the PASCAL ${ }^{\circledR}$ dynamic contour tonometer. The PASCAL ${ }^{\circledR}$ tonometers used in the study and the consumable products furnished for use by the investigators at no cost by Ziemer Ophthalmology. 


\section{References}

1. Ehlers N, Bramsen T, Sperling S. Applanation tonometry and central corneal thickness. Acta Ophthalmol (Copenh). 1975;53(1):34-43.

2. Herdener S, Pache M, Lautebach S, Funk J. Dynamic contour tonometry (DCT) versus Goldmann applanation tonometry (GAT) - a comparison of agreement and reproducibility. Graefes Arch Clin Exp Ophthalmol. 2007;245(7):1027-1030.

3. Kaufmann C, Bachmann LM, Thiel MA. Comparison of dynamic contour tonometry with Goldmann applanation tonometry. Invest Ophthalmol Vis Sci. 2004;45(9):3118-3121.

4. Sullivan-Mee M, Gerhardt G, Halverson KD, Qualls C. Repeatability and reproducibility for intraocular pressure measurement by dynamic contour, ocular response analyzer, and Goldmann applanation tonometry. J Glaucoma. 2009;18(9):666-673.

5. Tonnu PA, Ho T, Sharma K, White E, Bunce C, Garway-Heath D. A comparison of four methods of tonometry: method agreement and interobserver variability. Br J Ophthalmol. 2005;89(7):847-850.

6. Barleon L, Hoffmann EM, Berres M, Pfeiffer N, Grus FH. Comparison of dynamic contour tonometry and Goldmann applanation tonometry in glaucoma patients and healthy subjects. Am J Ophthalmol. 2006; 142(4):583-590.

7. Burvenich H, Burvenich E, Vincent C. Dynamic contour tonometry (DCT) versus non-contact tonometry (NCT): a comparison study. Bull Soc Belge Ophtalmol. 2005;(298):63-69.

8. Ceruti P, Morbio R, Marraffa M, Marchini G. Comparison of Goldmann applanation tonometry and dynamic contour tonometry in healthy and glaucomatous eyes. Eye (Lond). 2009;23(2):262-269.

9. Erdurmus M, Totan Y, Hepsen IF, Yagci R. Comparison of dynamic contour tonometry and noncontact tonometry in ocular hypertension and glaucoma. Eye (Lond). 2009;23(3):663-668.

10. Francis BA, Hsieh A, Lai MY, et al. Effects of corneal thickness, corneal curvature, and intraocular pressure level on Goldmann applanation tonometry and dynamic contour tonometry. Ophthalmology. 2007; 114(1):20-26.

11. Jordao ML, Lupinacci AP, Ferreira EL, Enomoto IJ, Costa VP. Influence of age, central corneal thickness, and quality score on dynamic contour tonometry. Eye (Lond). 2009;23(6):1364-1369.

12. Kniestedt C, Lin S, Choe J, Bostrom A, Nee M, Stamper RL. Clinical comparison of contour and applanation tonometry and their relationship to pachymetry. Arch Ophthalmol. 2005;123(11):1532-1537.

13. Tonnu PA, Ho T, Newson T, et al. The influence of central corneal thickness and age on intraocular pressure measured by pneumotonometry, non-contact tonometry, the Tono-Pen XL, and Goldmann applanation tonometry. Br J Ophthalmol. 2005;89(7):851-854.

14. Boehm AG, Weber A, Pillunat LE, Koch R, Spoerl E. Dynamic contour tonometry in comparison to intracameral IOP measurements. Invest Ophthalmol Vis Sci. 2008;49(6):2472-2477.

15. Kniestedt C, Nee M, Stamper RL. Dynamic contour tonometry: a comparative study on human cadaver eyes. Arch Ophthalmol. 2004;122(9): 1287-1293.

16. Brandt JD, Beiser JA, Kass MA, Gordon MO. Central corneal thickness in the Ocular hypertension treatment study (OHTS). Ophthalmology. 2001;108(10):1779-1788.
17. La Rosa FA, Gross RL, Orengo-Nania S. Central corneal thickness of Caucasians and African Americans in glaucomatous and nonglaucomatous populations. Arch Ophthalmol. 2001;119(1):23-27.

18. Shimmyo M, Ross AJ, Moy A, Mostafavi R. Intraocular pressure, Goldmann applanation tension, corneal thickness, and corneal curvature in Caucasians, Asians, Hispanics, and African Americans. Am J Ophthalmol. 2003;136(4):603-613.

19. Gunvant P, Broadway DC, Watkins RJ. Repeatability and reproducibility of the BVI ultrasonic pachymeter. Eye (Lond). 2003;17(7):825-828.

20. Argus WA. Ocular hypertension and central corneal thickness. Ophthalmology. 1995;102(12):1810-1812.

21. Bhan A, Browning AC, Shah S, Hamilton R, Dave D, Dua HS. Effect of corneal thickness on intraocular pressure measurements with the pneumotonometer, Goldmann applanation tonometer, and Tono-Pen. Invest Ophthalmol Vis Sci. 2002;43(5):1389-1392.

22. Copt RP, Thomas R, Mermoud A. Corneal thickness in ocular hypertension, primary open-angle glaucoma, and normal tension glaucoma. Arch Ophthalmol. 1999;117(1):14-16.

23. Gunvant P, Baskaran M, Vijaya L, et al. Effect of corneal parameters on measurements using the pulsatile ocular blood flow tonograph and Goldmann applanation tonometer. Br J Ophthalmol. 2004;88(4): 518-522.

24. Herndon LW, Choudhri SA, Cox T, Damji KF, Shields MB, Allingham RR. Central corneal thickness in normal, glaucomatous, and ocular hypertensive eyes. Arch Ophthalmol. 1997;115(9):1137-1141.

25. Stodtmeister R. Applanation tonometry and correction according to corneal thickness. Acta Ophthalmol Scand. 1998;76(3):319-324.

26. Wolfs RC, Klaver CC, Vingerling JR, Grobbee DE, Hofman A, de Jong PT. Distribution of central corneal thickness and its association with intraocular pressure: the Rotterdam study. Am J Ophthalmol. 1997;123(6):767-772.

27. Gunvant P, O'Leary DJ, Baskaran M, Broadway DC, Watkins RJ, Vijaya L. Evaluation of tonometric correction factors. J Glaucoma. 2005;14(5):337-343.

28. Stodtmeister R, Kron M, Gaus W. IOP measurement and central corneal thickness. Br J Ophthalmol. 2002;86(1):120-121.

29. de Saint Sardos A, Kamdeu Fansi A, Chagnon M, Harasymowycz PJ. Intraocular pressure adjusted for central corneal thickness as a screening tool for open-angle glaucoma in an at-risk population. Can J Ophthalmol. 2009;44(5):571-575.

30. Sullivan-Mee M, Halverson KD, Saxon GB, et al. The relationship between central corneal thickness-adjusted intraocular pressure and glaucomatous visual-field loss. Optometry. 2005;76(4):228-238.

31. Orssengo GJ, Pye DC. Determination of the true intraocular pressure and modulus of elasticity of the human cornea in vivo. Bull Math Biol. 1999;61(3):551-572.

32. Kotecha A, White ET, Shewry JM, Garway-Heath DF. The relative effects of corneal thickness and age on Goldmann applanation tonometry and dynamic contour tonometry. Br J Ophthalmol. 2005;89(12): 1572-1575.

33. Medeiros FA, Sample PA, Weinreb RN. Comparison of dynamic contour tonometry and Goldmann applanation tonometry in African American subjects. Ophthalmology. 2007;114(4):658-665.
Clinical Ophthalmology

\section{Publish your work in this journal}

Clinical Ophthalmology is an international, peer-reviewed journal covering all subspecialties within ophthalmology. Key topics include: Optometry; Visual science; Pharmacology and drug therapy in eye diseases; Basic Sciences; Primary and Secondary eye care; Patient Safety and Quality of Care Improvements. This journal is indexed on Submit your manuscript here: http://www.dovepress.com/clinical-ophthalmology-journal

\section{Dovepress}

PubMed Central and CAS, and is the official journal of The Society of Clinical Ophthalmology (SCO). The manuscript management system is completely online and includes a very quick and fair peer-review system, which is all easy to use. Visit http://www.dovepress.com/ testimonials.php to read real quotes from published authors. 